\title{
AUTONOMIA PROFISSIONAL DO ENFERMEIRO NO ATENDIMENTO DAS NECESSIDADES HUMANAS BASICAS
}

\author{
Tamara Iwanow Cianciarullo*
}

CIANCIARULO, T. I. Autonomia profissional do enfermeiro no atendimento das necessidades humanas básicas. Rev. Esc. USP, São Paulo, 22 ( $\mathrm{n} .^{\circ}$ especial): 43-46, Jun. 1988.

A autora aborda a questão "autonomia do enfermeiro como profissional liberal" e enfatiza o fato desta autonomia existir apenas no discurso de alguns enfermeiros. Ressalta, ainda, que a realidade da nossa prática tem mostrado que os enfermeiros continuam submissos aos vários profissionais da área de saúde e poucos esforços têm concentrado para melhorar a estrutura organizacional da assistência à clientela, baseada em suas reais necessidades.

UNITERMOS: Enfermagem como profissão. Assistência de enfermagem.

A autonomia do enfermeiro como profissional liberal, tem caracterizado no decorrer dos últimos trinta anos, o nosso discurso, sempre presente em grandes ocasiões, em eventos como este, em congressos e outros tipos de reuniões.

A realidade da nossa prática, no entanto, tem muito pouco a ver com este discurso, quando o enfermeiro é ainda submisso ao médico, ao administrador hospitalar e algumas vezes até a outros profissionais da área de saúde, definindo-se aqui o submisso, como aquele disposto à obediência.

LANDMAN (1985), em sua obra Medicina não é saúde, afirma que é importante derrubar o sistema de hierarquia que tradicionalmente subordina as enfermeiras à ação do médico, de modo que ela possa contribuir melhor para o compromisso social pela saúde coletiva.

WAGNER (1980), citado por MELO (1986) afirma que a história da enfermagem tem se caracterizado, não por uma crescente autonomia profissional, responsabilidade e prestígio, como algumas vezes tem sido retratada por líderes profissionais, mas por uma diminuição de independêncla, aumentada estratificação e divisão de trabalho, além de crescente revolta contra as "condições de linha de montagem".

\footnotetext{
- Professar Assistente Doutor do Departamento de Enfermagem Médico-Clrúrglca da Escola de Enfermagem da USP.
} 
SINDA (1984) afirma que é um fato, que a grande maioria das enfermeiras não são profissionais independentes, mas constituem um grupo de pessoas empregadas, prestando conta não aos pacientes de que cuidam mas às instituições que as empregam.

Podemos nos considerar como as pessoas mais ocupadas do universo de trabalho, cujo tempo e esforços devem estar concentrados nas atividades rotineiras, mas se não quisermos que outros profissionais planejem e nos orientem nas nossas atividades, teremos que reservar um tempo para pensar, planejar e iniciar novas ações, afirma HASSENPLUG (1977). Há muito tempo, continua Hassenplug (1977), que as enfermeiras têm executado ações que outros acham que elas devem fazer e como conseqüência o papel das enfermeiras tem sido condicionado por estranhos à enfermagem.

Em nossa experiência docente-assistencial, pudemos perceber claramente, que mesmo quando investidos de poderes delegados a nós por médicos e/ou administradores, raras são as ocasiões em que usamos este poder para melhorar a assistência à nossa clientela; preferimos sempre concentrar nossos esforços na estrutura organizacional da instituição, ao invés de nos orientarmos para a estrutura organizacional da assistência à nossa clientela, baseadas em suas reais necessidades.

Ao mesmo tempo ensinamos aos nossos alunos, que eles serão profissionais liberais, autônomos e responsáveis por seus atos junto à sua clientela. A realidade no entanto continua distante do discurso, que agora já assume o papel de ensinamento. Como se dará o processo da aprendizagem neste conflito de colocações e as realidades tão distantes? Certamente precisamos rever as condições de autonomia das nossas ações profissionais, para que os nossos alunos atuais, não se tornem amanhã os mesmos executores de ações delegadas, mas não conquistadas.

Somos na grande maioria mulheres, e mulheres brasileiras que sofrem de um desnível de rendimento importante. Somente $11 \%$ das mulheres com mais de 12 anos de instrução, recebem mensalmente mais de dez salários mínimos, enquanto que para o sexo masculino este mesmo indicador passa para $49 \%$. Certamente uma grande proporção de enfermeiras brasileiras não está incluída nesses $11 \%$. Acresce-se o fato de que, o poder de decisão na área de saúde encontra-se na autoridade carismática do médico garantida e validada, segundo LANDMAN (1985), através do exercício regular da profissão, no qual ele se investe dos quatro atributos de todas as profissões carismáticas: ensino, cura, comando e proteção.

Poder-se-ia dizer que as enfermeiras possuem também estes atributos. No entanto, o ensino de enfermagem ainda se fundamenta em práticas tradicionais e em professores que reprimem mais do que estimulam, constituindo o chamado "Laboratório da Docilidade", referido por LOYOLA (1984).

A cura, cujo domínio é caracterizado pela tecnologia médica, seria substituída nessa seqüência analítica, pelo cuidado, representado, pela tecnologia desenvolvida pelas enfermeiras, fundamentada na ciência e 
arte de assistir o ser humano no atendimento das suas necessidades humanas básicas, de torná-lo independente desta assistência, quando possível pelo ensino do Autocuidado; de recuperar, manter e promover a saúde em colaboração com outros profissionais (HORTA 1979). A arte, seria a capacidade criativa de usar a ciência em benefício da sua clientela e a ciência de enfermagem compreenderia o estudo das necessidades humanas básicas, dos fatores que alteram a sua manifestação e atendimento e do tipo de assistência a ser prestada (HORTA 1979).

As atividades que visam a recuperação, a manutenção e a promoção da saúde em colaboração com outros profissionais, refletem-se em seus limites, no conteúdo das respostas obtidas por LOYOLA (1984): a enfermagem é aquela que tem que fazer tudo o que os outros deixaram de fazer.

Assim, mesmo em relação ao nosso próprio âmbito de ação, preconizado pelas teoristas, percebemos uma subissão em nome das necessidades do paciente não aîendidas por outros profissionais, contribuindo para uma mistificação da chamada área de interdependência. A afirmação encontrada por LOYOLA (1984) em suas entrevistas, de que a "enfermeira gosta de ser subalterna, é comodista e não tem respaldo da classe", encaminha o processo da interdependência para o da dependência ao poder constituído, qualquer que ele seja.

Para o comando exercido pela enfermeira sobre seus "comandos" equipe de enfermagem, que teoricamente poderia lhe fornecer o carisma, reproduz a ideologia dominante dos outros profissionais ou da própria organização administrativa, diminuindo a sua própria capacidade de influência.

E, a proteção, que ela poderia exercer em função da sua clientela, esbarra no "horror que a enfermeira tem de ser responsável pelos seus atos" LOYOLA (1984) e no medo de errar se não seguir as ordens de alguém, na nossa opinião.

Nós enfermeiras, não nos autorizamos a oportunidade de errar, segundo o nosso próprio conceito desenvolvido há anos e referendado pelas práticas administrativas (seguimos rigorosamente as normas e as rotinas) e pelas práticas profissionais determinadas por outrem (ordem médicas e utlimamente de até outros profissionais). Se temos medo de assumir riscos, se somos uma minoria por uma conceituação própria, a submissão no ensino e na prática de tal modo que até os pacientes a percebem, se estendemos os nossos papéis maternos até o nosso campo de atuação, onde o marido-zangão é o médico-homem; se agimos como guardiãs destes mesmos médicos ao invés de advogarmos as causas dos nossos pacientes ou dos grupos da comunidade com os quais trabalhamos; se conseguimos construir os "laboratórios de docilidade" em nossas escolas, e se perce. bemos as relações de poder como algo distante e fora do nosso alcance, posso afirmar, que, somos uma população em risco de "desaparecimento" e que nem mesmo a máxima validação e operacionalização das novas teorias de enfermagem será capaz de reverter este processo de "desaparecimento" sem um profundo estudo crítico construtivo da dimensão social do saber, do ensinar, do reaprender a fazer enfermagem. 
CIANCIARULLO, T.I. Professional autonomy of the nurse for the fulfillment of the basic human needs. Rev. Esc. Ent. USP, São Paulo, 22 (special issue): 43-46, June 1988.

The author approaches the issue "authonomy of the nurse as a liberal professional". She emphasizes that this authonomy exists only in the speech of some nurses. She also points out that our practice has shown that the nurses are still subordinate to several professionals of the health team and a little has been done to ameliorate the organizational structure of caring, based on the real needs of the clients.

UNITERMS: Nursing. Nursing care.

\section{REFERENCIAS BIBLIOGRAFICAS}

1. HASSENPLUG, L. W. Resocializing the nursing role. In: NATIONAL LEAGUE FOR NURSING. Power use it or lose it. New York, 1977. p. 1-5. (Publ. n. ${ }^{\circ}$ 52-1675).

2. HORTA, W. A. Processo de enfermagem. São Paulo, EPU, 1979, 99 p.

3. LANDMANN, J. Medicina não é saúde. Rio de Janeiro, Nova Fronteira, 1985.

4. LOYOLA, C. M. Os doce(i)s corpos do hospital: as enfermeiras e o poder institu. cional na estrutura hospitalar. Rio de Janeiro, 1984. $137 \mathrm{p}$. (Tese de doutorado Instituto de Filosofia e Ciências Sociais da UFRJ).

5. MELO, C. Divisão social do trabalho e enfermagem. São Paulo. Cortez, 1986.

6. SINDA, M. T. S. The powerlessness of the nurse and its effect on the client. 